\title{
LA RESCISIÓN CONCURSAL DE LES MODIFICACIONES ESTRUCTURALES: EL INTERÉS DE LOS ACREEDORES FRENTE AL INTERÉS DE LOS SOCIOS
}

Teodora Jacquet Yeste 


\section{Planteamiento.}

La relación entre el régimen del concurso de acreedores y el de las modificaciones estructurales de las sociedades mercantiles ha sido un tema que ha suscitado interés en la doctrina y en la jurisprudencia desde la aprobación de la Ley Concursal (en adelante, LC). Uno de los aspectos de esta relación es el de la afectación del concurso sobre las modificaciones estructurales ya inscritas en el Registro Mercantil, y más en concreto el de si este tipo de operaciones societarias, celebradas dentro del periodo de dos años anteriores a la declaración de concurso, puede ser rescindido a través de una acción de reintegración concursal del art.71 LC. La duda surge porque el art.47 Ley de Modificaciones Estructurales (en adelante, LME) establece que ninguna fusión podrá ser impugnada tras su inscripción siempre que se haya realizado de conformidad con las previsiones de la ley, guardando la LC silencio al respecto. En este trabajo pretendemos aportar elementos de análisis a favor de entender el silencio de la LC en el sentido de permitir la rescisión de las modificaciones estructurales, básicamente por coherencia con la finalidad del concurso y con la función que cumplen las acciones de reintegración concursal.

\section{II.- Las acciones de reintegración y la finalidad del concurso.}

Uno de los elementos normativos del sistema concursal que contribuye de manera más decisiva a la consecución de la finalidad del concurso, esto es la maximización del valor del patrimonio del deudor en interés del conjunto de acreedores, es sin lugar a dudas el régimen de las acciones de reintegración concursal previsto en los arts.71 a 73 LC. En efecto, las acciones de reintegración concursal se erigen como un mecanismo de recuperación y reconstrucción del patrimonio del con- cursado, que ha podido verse mermado por actos del deudor llevados a cabo en un momento anterior a la declaración de concurso. Dado que en épocas próximas a la insolvencia el deudor puede llevar a cabo conductas estratégicas que pongan en peligro la satisfacción del interés de los acreedores y más en concreto puede llevar a cabo actos que perjudiquen a la masa activa del concurso provocando la imposibilidad de lograr la solución que maximice el valor del patrimonio del deudor y que mejor satisfaga al conjunto de acreedores, el propósito de las acciones de reintegración no es otro que el de restaurar el patrimonio del deudor concursado al que debiera existir si no se hubieran producido dichos actos, anulando pues los efectos que éstos produjeron y situando a la masa activa en las mejores condiciones posibles para satisfacer a los acreedores.

A tal fin el art.71 LC considera rescindibles los actos perjudiciales para la masa activa realizados por el deudor dentro de los dos años anteriores a la fecha de la declaración, aunque no hubiere existido intención fraudulenta. El perjuicio patrimonial se presume, sin admitir prueba en contrario, cuando se trate de actos de disposición a título gratuito, salvo las liberalidades de uso, y de pagos $u$ otros actos de extinción de obligaciones cuyo vencimiento fuere posterior a la declaración del concurso, excepto si contasen con garantía real. En otro tipo de actos, el perjuicio patrimonial se presume salvo prueba en contrario, como en los actos dispositivos a título oneroso realizados a favor de alguna de las personas especialmente relacionadas con el concursado, la constitución de garantías reales a favor de obligaciones preexistentes o de las nuevas contraídas en sustitución de aquéllas o los pagos u otros actos de extinción de obligaciones que contasen con garantía real y cuyo vencimiento fuere posterior a la declaración del concurso. 


\section{III.- Los actos irrescindibles y su racionalidad.}

Con todo, y a pesar de la importancia que las acciones de reintegración adquieren para una adecuada consecución de la finalidad del concurso, la LC establece una serie de actos que en ningún caso podrán ser objeto de rescisión y que, por su carácter excepcional, deben interpretarse como una lista taxativa y restrictiva, debiendo quedar fundamentadas de forma coherente con la consecución de la finalidad del concurso o bien con la protección de otros intereses que se entiendan superiores al del concurso. Así, el art.71.5 LC enumera los siguientes:

1. ${ }^{\circ}$ Los actos ordinarios de la actividad profesional o empresarial del deudor realizados en condiciones normales.

2. ${ }^{\circ}$ Los actos comprendidos en el ámbito de leyes especiales reguladoras de los sistemas de pagos y compensación y liquidación de valores e instrumentos derivados.

3. ${ }^{\circ}$ Las garantías constituidas a favor de los créditos de Derecho Público y a favor del FOGASA en los acuerdos o convenios de recuperación previstos en su normativa específica.

Conviene detenerse a averiguar la racionalidad de cada una de estas excepciones, puesto que ello va a contribuir a dotarnos de argumentos en contra de la pretendida irrescindibilidad de las modificaciones estructurales ante una acción de reintegración concursal.

En relación al primer supuesto, y dejando a un lado el hecho de que se trate de actos que, por haber sido realizados en condiciones normales, difícilmente generen un perjuicio al patrimonio del deudor, resulta evidente que la irrescindibilidad de dichos actos contribuye a la continuidad de la actividad empresarial al evitar la desconfianza que los operadores podrían sentir por mantener relaciones comerciales, aunque de carácter ordinario y habituales en el sector económico en el que se desarrolle la actividad, con quienes se encuentran en una situación próxima a la insolvencia. Dicha desconfianza, y la consiguiente dificultad para el deudor de lograr proveedores, por ejemplo, dificulta la continuidad de la actividad empresarial y, ello, a su vez, precipita o agrava la insolvencia en el caso de que aquella actividad sea viable económicamente y su conservación sea la solución que maximice el valor del patrimonio del deudor. De manera que esta excepción ofrece seguridad al normal funcionamiento del mercado en relación con estos sujetos, contribuyendo a la conservación de la actividad empresarial y a la consecución de la finalidad del concurso, en plena coherencia con el propósito, ya expuesto, de las acciones de reintegración concursal.

En cuanto a la segunda excepción, la LC hace una remisión a las leyes especiales, de aplicación preferente, en esta materia. En concreto, la Disposición adicional segunda LC recoge el régimen especial aplicable a entidades de crédito, empresas de servicios de inversión y entidades aseguradoras, estableciendo que en los concursos de entidades de crédito o entidades legalmente asimiladas a ellas, empresas de servicios de inversión y entidades aseguradoras, así como entidades miembros de mercados oficiales de valores y entidades participantes en los sistemas de compensación y liquidación de valores, se aplicarán las especialidades que para las situaciones concursales se hallen establecidas en su legislación específica, salvo las relativas a composición, nombramiento y funcionamiento de la 
administración concursal. Este régimen especial protege un interés diferente al de las acciones de reintegración, puesto que tiene en cuenta el riesgo inherente a los referidos sistemas de pago y mercados financieros, que obliga a preservar de forma particular la confianza del participante en los mismos y en consecuencia a limitar las posibilidades de rescisión de los actos que celebre. En este sentido, el legislador ha decidido, al hacer inatacables estos actos en sede concursal, que debe prevalecer la firmeza de las operaciones realizadas en el marco de estos sistemas a las entidades financieras citadas y evitar los efectos perniciosos para el sistema financiero que provocaría la posibilidad de rescindirlos a través de las acciones de reintegración concursal.

En cuanto a la tercera excepción, parece responder a la política legislativa en la LC de especial protección a las expectativas de cobro de los créditos de Derecho público, presente no sólo en su clasificación como créditos privilegiados sino también en la remisión a su normativa específica en determinadas actuaciones (v.gr., exoneración del pasivo insatisfecho). La irrescindibilidad de las garantías a favor de dichos créditos no sería más que otra medida adicional derivada de la voluntad política de protección de su función recaudatoria a favor del erario público, como interés prevalente al del concurso.

Finalmente, además de estos tres tipos de actos declarados irrescindibles por el art.71.5 LC, hemos de tener presente el art.71 bis LC, que declara que no serán rescindibles los acuerdos de refinanciación alcanzados por el deudor, así como los negocios, actos y pagos, cualquiera que sea la naturaleza y la forma en que se hubieren realizado, y las garantías constituidas en ejecución de los mismos, cuando se reúnan determinadas condiciones, fijadas en el mismo precepto.
Esta irrescindibilidad se dirige sin lugar a dudas a promocionar unos acuerdos de refinanciación que, de no existir dicha norma, difícilmente se celebrarían debido al elevado riesgo de rescisión, motivando de esta manera a los operadores financieros a refinanciar a las empresas en dificultades. También en este caso se trata de una excepción que persigue la maximización del valor del patrimonio del deudor a través de la conservación de la actividad empresarial y que, en la medida en que ésta sea viable económicamente y así quede patente en el plan de viabilidad al que deben responder aquellos actos, contribuye a la máxima satisfacción de los intereses de los acreedores, en definitiva a la mejor solución a la situación de insolvencia del deudor.

\section{IV.- El art. 47 LME y la pretendida resistencia al concurso de las modificaciones estructurales.}

Como se puede comprobar en esta breve referencia a las excepciones a la regla general de rescindibilidad de los actos perjudiciales para la masa celebrados dentro de los dos años anteriores a la declaración de concurso, cada una de ellas responde a una racionalidad concreta y su determinación en la LC responde a una reflexión y ponderación de intereses que el legislador ha previsto de forma expresa a la vez que restrictiva, entendiendo que la alteración del criterio general fijado en rescindir todos aquellos actos que puedan resultar perjudiciales para la masa a fin de maximizar el valor del patrimonio del deudor requiere de una previsión explícita, que estará fundamentada en una mejor consecución de la finalidad del concurso o en la protección de otros intereses que puedan entenderse como superiores por parte del legislador.

Sin embargo, y a pesar del silencio de la LC al respecto, ha surgido en la doctrina y en la jurispru- 
dencia una corriente según la cual las modificaciones estructurales en las que haya podido participar la concursada en el período de dos años anteriores a la declaración de concurso tampoco podrán ser objeto de rescisión. Y ello fundamentalmente por aplicación del art.47 LME, que regula la que se ha dado en llamar cuasi-inimpugnabilidad de las fusiones inscritas, al disponer que ninguna fusión podrá ser impugnada tras su inscripción siempre que se haya realizado de conformidad con las previsiones de esta Ley, quedando a salvo, en su caso, los derechos de los socios y de los terceros al resarcimiento de los daños y perjuicios causados.

Este precepto ha llevado, como apuntábamos, a un importante sector doctrinal a negar la posibilidad de ejercicio de la rescisoria concursal frente a modificaciones estructurales ${ }^{1}$, siendo esta también la postura acogida por el Tribunal Supremo, en concreto en la Sentencia de 21 de noviembre de $2.016^{2}$. Son varios los argumentos esgrimidos a favor de estas tesis. Partiendo de la consideración de la LME como ley especial frente a la LC, la aplicación del art.47 LME se impone interpretando que prohíbe cualquier acción que pretenda la ineficacia de la modificación estructural, no sólo la nulidad sino también la rescisión concursal. De manera que no puede aceptarse la rescisión de la modificación concursal a través de la acción de reintegración concursal, pues de lo contrario se estaría activando un derecho de oposición extemporáneo a favor de los acreedores, cuando la LME ya les atribuye, en su art.44, un derecho a oponerse a la modificación, y no sería aceptable que los acree- dores que no ejercitaron tal derecho en tiempo, acudan posteriormente a la rescisoria concursal.

En esta interpretación en contra de la rescindibilidad concursal de las modificaciones estructurales se repite de forma insistente pero poco concreta que la rescindibilidad de tales operaciones generaría inseguridad jurídica, siendo las consecuencias del éxito de una eventual impugnación graves. En efecto, del análisis del art. 73 LC se deduce que podrían declararse ineficaces alguno o varios de los pagos recibidos en concepto de precio, que deberían ser reintegrados por los vendedores a la masa activa (con sus frutos e intereses). Esta defensa de la seguridad jurídica que la doctrina atribuye al art.47 LME se adecúa, según estos mismos autores, a las previsiones de las Directivas comunitarias tercera (78/855/CEE20) y sexta (82/891/CEE21), en materia de fusiones y escisiones, según las cuales "...es preciso, con miras a garantizar la seguridad jurídica en las relaciones tanto entre las sociedades interesadas (que participen en la escisión) como entre éstas y los terceros, así como entre los accionistas, limitar los casos de nulidad y establecer, por un parte, el principio de la regularización cada vez que sea posible, y por otra un plazo breve para invocar la nulidad." La trascendencia de los efectos de las modificaciones estructurales en el ámbito patrimonial (mediante la transmisión a título universal) y en relación a la posible integración de los socios de la sociedad transmitente en la adquirente, les lleva a afirmar el principio de la inatacabilidad o inmodificabilidad de las modificaciones estructurales inscritas. Según el TS, el legislador de la LME,

\footnotetext{
${ }^{1}$ En esta línea, vid. Cerdá Albero, F., "rescisión concursal y modificaciones estructurales traslativas (SJM 2 Las Palmas de Gran Canaria 12.1.2.2011), Anuario de Derecho Concursal, núm.27, 2012, págs.387-428; Sánchez-Calero Guilarte, J. y Fernández Torres, I., "Fusiones apalancadas, asistencia financera y concurso (oportunidad y acierto del art.35 LME), Revista de Derecho Concursal y Paraconcursal, núm.14, 2011, págs.109-133; González Navarro, B.A., "La rescisión de las modificaciones estructurales societarias", en Beltrán, E. y Sanjuán, E. (dirs.), La reintegración de la masa, Thomson Reuters, 2012, págs.181-198.

${ }^{2}$ Roj 5136/2016, ponente Ignacio Sancho Gargallo.
} 
al establecer este principio, subviene a las exigencias de la seguridad jurídica, que se concreta en el mantenimiento de estos actos jurídicosocietarios, y sirve también para evitar las enormes dificultades prácticas, objetivas y jurídicas que conllevaría deshacer la modificación estructural inscrita.

\section{V.- La protección del interés de la so- ciedad frente al interés de los sociosl.}

Conviene sin embargo dotar de contenido a estas referencias a la seguridad jurídica en el sentido de entender la verdadera función del art.47 LM, el verdadero fundamento de la prohibición y el interés último que quiere protegerse con ella. Está claro que el art.47 LME no busca proteger a los acreedores. Si acaso estos se ven protegidos por otras normas de la misma ley, como son el derecho de oposición y las reglas de atribución de responsabilidad en caso de obligaciones incumplidas. Teniendo en cuenta que el proyecto de modificación estructural lo redactan y suscriben los administradores de cada una de las sociedades que participan en la operación y dichos administradores han de actuar, por orden de los deberes impuestos por la Ley de Sociedades de Capital, en el mejor interés de la sociedad, y que el proyecto ha de ser aprobado por los socios de cada sociedad, no hay duda que el interés perjudicado por una posible ineficacia de la operación serían el interés social, que no es otro que la suma de los intereses particulares de los socios de la sociedad.

Tampoco es dudoso que este no es precisamente el interés principal protegido por el concurso en general ni por las acciones de reintegración en particular. $Y$ es que cuando una sociedad se adentra en una situación de insolvencia podría decirse que los acreedores sustituyen a los socios como titulares residuales de aquella, por consiguiente en sede concursal el interés prioritario a proteger pasa a ser el de los acreedores, que son, en virtud de aquella nueva condición que adoptan, quienes sufren los efectos de las decisiones tomadas por los administradores de la sociedad concursada. Porque cuando la sociedad se encuentra en estado de insolvencia la protección de los acreedores corresponde propiamente no al Derecho de sociedades sino al Derecho concursal, que prevé específicamente un conjunto de medidas tendentes a evitar conductas estratégicas de los administradores en épocas próximas a la insolvencia que ponen en peligro la satisfacción del interés de los acreedores.

De manera que cuando se ha realizado una modificación estructural en la que ha participado alguna sociedad que en los dos años posteriores ha sido declarada en concurso, surge un conflicto de intereses: por un lado, el interés de los acreedores en maximizar el valor del patrimonio de la empresa y lograr así una mejor satisfacción de sus créditos, y por el otro, el de los socios en mantener la eficacia de la modificación estructural en cuestión. Intereses contrapuestos que deben ser ponderados a efectos de decidir cuál prima sobre cuál. De hecho, la existencia de un conflicto de intereses y necesaria ponderación de los mismos no es una situación nueva en relación al régimen de las acciones de reintegración concursal, puesto que es lo que hemos visto que sucede en el caso de los actos comprendidos en el ámbito de leyes especiales reguladoras de los sistemas de pagos y compensación y liquidación de valores e instrumentos derivados, en que la LC ha sido explícita en dar preeminencia a la protección de aquellos terceros que podrían verse perjudicados por la posible ineficacia de los actos en cuestión. En cambio, en relación a las modificaciones estructurales, la LC no ha sido explícita en este sentido, al contrario se ha mantenido en silencio, por lo que éste silencio no puede interpretarse de otra ma- 
nera que en el sentido de mantener la rescindibilidad de las modificaciones estructurales, como la de cualquier otro acto que resulte perjudicial para la masa activa y que no haya sido expresamente declarado como irrescindible. Así lo han entendido también algunos autores y decisiones judiciales al considerar a la LC como ley especial frente a la LME en relación a aquellos actos societarios llevados a cabo en periodos próximos a la insolvencia y suponer que a la hora de señalar qué actos, contratos, negocios quedan protegidos frente a la reintegración, la LC, al no incluir a las modificaciones estructurales, entiende que estas son actos perfectamente rescindibles, una vez declarado el concurso .

A este argumento, que nos parece definitivo, cabe añadir las dudas, ya apuntadas en la doctrina, de la consideración de la acción de reintegración concursal como una acción de impugnación en el contexto del art.47.1 LME. Según aquellos que defienden la irrescindibilidad de las modificaciones estructurales, el art. 47.1 LME emplea el término «impugnación», que es más amplio que el de nulidad, para abarcar cualquier acción que pretenda la ineficacia de la modificación estructural una vez inscrita en el Registro Mercantil. Pero, como afirman otros, la acción de reintegración no es una acción de impugnación, que persiga la concurrencia de vicios de ineficacia, sino una acción rescisoria, especial, propia del procedimiento concursal, que busca la reintegración de bienes y derechos a la masa activa, cuando existe un perjuicio objetivo para la misma, aunque el acto en cuestión sea válido y eficaz. La reintegración de la masa activa en el concurso de acreedores se lleva a cabo a través de una acción que se califica como rescisoria, si bien constituye una rescisoria especial propia del procedimiento concursal. El ejercicio de esta rescisoria concursal se sujeta a la concurrencia de dos requisitos: que se trate de actos realizados por el deudor en los dos años anteriores a la declaración de concurso y que el acto sea perjudicial para la masa activa, ni se requiere la intención fraudulenta, ni que exista vinculación entre el acto objeto de impugnación y el estado de insolvencia del concursado, de forma que no es obvia la equiparación de acción de impugnación y acción rescisoria concursal a los efectos de interpretar el art.47 LME.

\section{VI.- Conclusión}

La coherencia con la finalidad del concurso y la configuración de las acciones de reintegración como instrumento fundamental para lograrla obligan a una interpretación favorable a la rescindibilidad de las modificaciones estructurales, a pesar de lo establecido por el art.47 LME. Por lo que la atención en casos de modificaciones estructurales realizadas en el periodo de dos años anteriores a la declaración de concurso debe centrarse en determinar si dicha operación realmente ha causado un perjuicio económico a la masa activa, no pudiendo aceptarse de ninguna manera que el art.47 LME pueda utilizarse para causar un perjuicio económico a la masa del concursado que ponga en peligro la maximización del patrimonio del deudor y en consecuencia la mejor satisfacción de los intereses de los acreedores. 
